\title{
EVALUASI ANTARMUKA PENGGUNA UNTUK MENINGKATKAN PENGALAMAN PENGGUNA DENGAN METODE HEURISTIC DAN THINK-ALOUD
}

\author{
Orin Cristina Br. Sianipar', Kurweni Ukar², Budi Permana ${ }^{3}$ \\ 1,2,3 STMIK LIKMI \\ E-mail : ocbr.sianipar@gmail.com ${ }^{1}$
}

\begin{abstract}
ABSTRAK
Penelitian ini bertujuan mengetahui kekurangan pada tampilan website Rumahdijual.com untuk meningkatkan kepuasan pengguna dengan metode Heuristic Evaluation (HE) dan Think-aloud (TA). Evaluasi menerapkan 7 dari 10 Usability Heuristic, dan menghasilkan nilai SUS di bawah standar yaitu 21.3 poin dan menemukan kesalahan tampilan terkait konten yang terlalu banyak, tampilan yang tidak diperbaharui, menu help dan tombol next, previous, close yang belum tersedia pada fitur lihat gambar. Evaluasi Ini membuktikan bahwa UI/UX pada aplikasi perlu perbaikan.
\end{abstract}

Kata kunci : User Interface (UI), User Experience (UX), Heuristic Evaluation (HE), Thinkaloud Evaluation (TA), Software Usability System (SUS)

\section{PENDAHULUAN}

Rumahdijual.com adalah salah satu website pencarian properti paling populer di Indonesia dengan jumlah kunjungan hampir 1 juta perbulan menurut kompasiana.com [1]. Memasuki tahun 2021 Rumahdijual.com tidak pernah lagi muncul dalam pencarian website jual-beli properti populer di Indonesia. Jika dilihat dari fitur yang ditawarkan website ini cukup lengkap, akan tetapi tidak banyak perubahan pada sisi Interface, yang sama seperti saat website ini diluncurkan pertama kali.

Pengaruh User Interface (UI) terhadap user experience (UX) untuk meningkatkan kunjungan website sangat menarik untuk dipelajari lebih jauh. Penelitian ini diharapkan dapat memberikan masukan untuk mengingatkan kemampuan website Rumahdijual.com dalam menyajikan informasi yang menarik bagi pengguna. Bukan hanya itu peningkatan website juga diharapkan memberikan kepuasan kepada pengguna ketika mencari informasi, sehingga pengguna tidak pindah ke webside lain dan jumlah transaksi jual-beli rumah pada website Rumahdijual.com dapat ditingkatkan.

\section{METODE PENELITIAN}

Heuristic Evaluation (HE) dan Think-aloud (TA) adalah metode evaluasi yang akan digunakan pada penelitian UI/UX Rumahdijual.com. Heuristic Evaluation (HE) adalah metode evaluasi usability yang membutuhkan ahli UI/UX untuk meninjau dan memberikan umpan balik pada tampilan suatu sistem berdasarkan Usability Heuristic atau pedoman [3]. Think-aloud adalah pengujian yang membutuhkan orang biasa sebagai responden untuk meninjau dan mengomentari tampilan suatu sistem saat mereka gunakan [4].

Alur penelitian yang dapat dilihat pada Gambar 1 menunjukkan bahwa setelah menyelesaikan rumusan masalah dan studi literatur terkait acuan penelitian evaluasi. Selanjutnya dibuat rancangan penelitian berupa pengumpulan data evaluasi, pembuatan 
kuesioner Heuristic checklist (HC), pembuatan skenario evaluasi serta pemilihan Software Usability System (SUS) untuk mengukur nilai kepuasan pengguna. SUS merupakan cara 'cepat dan kotor' untuk mengukur kegunaan suatu produk yang telah digunakan secara luas oleh berbagai industri untuk menguji berbagai sistem dan aplikasi, termasuk perangkat keras, perangkat lunak, perangkat seluler, situs web, dan aplikasi [7].

Pembuatan rancangan penelitian diperlukan untuk menghindari kegagalan pada evaluasi. Pengumpulan data menggunakan data kualitatif yang berbentuk laporan lisan, seperti wawancara atau laporan tertulis. Pada evaluasi Heuristik penelitian menggunakan 3 orang evaluator, mengikuti saran Nielsen, J., dan Molich, R. yang berpendapat bahwa dibutuhkan 3 sampai 5 orang evaluator untuk melakukan evaluasi heuristik [5]. Evaluasi Think-aloud menggunakan 10 responden, mengikuti hasil penelitian Alroobaea, Roobaea \& Mayhew, P.J. yang menunjukkan bahwa 10 responden dapat menemukan minimum $82 \%$ permasalahan dengan rata-rata permasalahan 94,686\% [2].

Dikarenakan kondisi PPKM (Pemberlakuan Pembatasan Kegiatan Masyarakat) yang saat ini terjadi akibat pandemik COVID-19. Penulis akan menggunakan Teknik Accidental Sampling yang mana penentuan sampel diambil berdasarkan peserta yang kebetulan ada di sekitar peneliti, pada kasus ini adalah orang-orang yang peneliti kenal dan bersedia mengikuti evaluasi [6].

Tahapan evaluasi Heuristik terdiri dari 7 proses yaitu pemberian briefing dan $\mathrm{HC}$ pada evaluator, kemudian evaluator mulai evaluasi dan mengisi kuesioner dengan memberikan komentar serta rating SUS sesuai dengan temuan kekurangan UI/UX aplikasi, jika sudah selesai hasil evaluasi akan dikirim Kembali kepada peneliti. Tahapan evaluasi Think-aloud hanya memiliki 5 proses yaitu menyiapkan bahan-bahan evaluasi, pemberian briefing dan mempersilakan responden untuk explore aplikasi, kemudian evaluasi dimulai dan peneliti bertanya terkait HC pada responden, mencatat hasil evaluasi. Jika sudah selesai maka evaluasi akan ditutup. Hasil evaluasi berupa komentar dan nilai SUS akan dianalisis dan dibahas, kemudian digabungkan dan dievaluasi hasil penggabungannya. Tahapan yang akan dilalui dalam penelitian secara terurut dapat dilihat pada Gambar 1 .

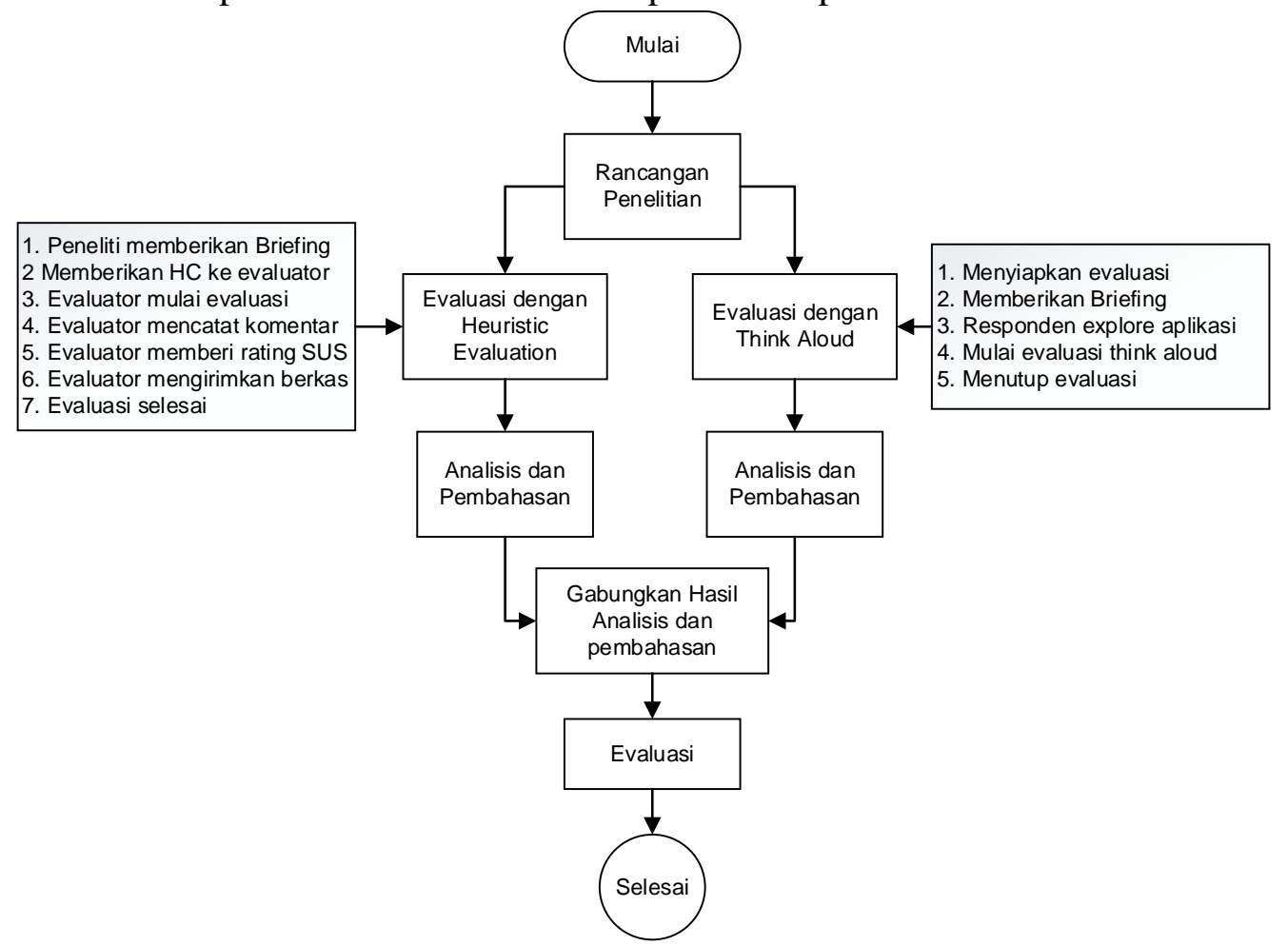

Gambar 1

Tahapan penelitian 


\section{HASIL DAN PEMBAHASAN}

Hasil pembahasan penelitian menggunakan metode Heuristic Evaluation (HE) dan Think-aloud (TA), dapat dilihat pada subbab 3.1 dan 3.2.

\subsection{HEURISTIK EVALUATION (HE)}

Metode Heuristic Evaluation (HE) yang digunakan, adalah metode evaluasi yang digabungkan dengan penilaian Software Usability System (SUS), sehingga hasil evaluasi tidak dinilai berdasarkan severity rating melainkan menggantinya dengan penilian SUS. Heuristic Evaluation (HE) yang dilakukan menggunakan 7 dari 10 Usability Heuristic yang kemudian dibuat menjadi kuesioner Heuristic Checklist (HC). Ketujuh Usability Heuristic yang digunakan yaitu:

1. Visibility of system status ( $\mathrm{HCO1)}$

2. User control and freedom (HCO3)

3. Error prevention (HCO5)

4. Recognition rather than recall (HCO6)

5. Flexibility and efficiency of use (HCO7)

6. Aesthetic and minimalist design (HCO8)

7. Help and documentation (HC10)

Kuesioner Heuristic Checklist (HC) terbagi menjadi 2 jenis penilaian yaitu berdasarkan komentar dan penilaian rating SUS. Hasil penilaian komentar dapat dilihat pada Tabel 1.

Tabel 1. Analisis Komentar pada Heuristic Checklist (HC)

\begin{tabular}{|l|l|l|}
\hline No & $\begin{array}{c}\text { Heuristic } \\
\text { Checklist } \text { (HC) }\end{array}$ & \multicolumn{1}{c|}{ Temuan } \\
\hline 1 & HC01 & Visibilitas kurang terlihat karena desain tidak uptodate \\
\hline 2 & HC02 & Konten/ informasi yang ditampilkan terlalu banyak \\
\hline 3 & HC03 & $\begin{array}{l}\text { - Tombol Close/Keluar tidak ada pada fitur lihat gambar } \\
\text { Tombol Next/Selanjutnya tidak ada pada fitur lihat gambar } \\
\text { - Tombol Preview/sebelumnya tidak ada pada fitur lihat } \\
\text { gambar } \\
\text { Tidak semua fungsi shortcut bisa dijalankan pada aplikasi }\end{array}$ \\
\hline 4 & HC05 & Tata Bahasa pesan error tidak baku \\
\hline 5 & HC06 & Hover tidak terlihat \\
\hline 6 & HC08 & Pembatas tiap bagian tidak jelas \\
\hline 7 & HC10 & Menu help tidak tersedia \\
\hline
\end{tabular}

Penilaian Software Usability System (SUS) dihitung menggunakan peraturan berikut ini:

1. Tiap pertanyaan urutan ganjil, skor SUS dikurangi 1

2. Tiap pertanyaan urutan genap, 5 dikurangi skor SUS

Persamaan poin 1 dan 2 dapat sebagai berikut:

Keterangan:

$$
f(x)\left\{\begin{aligned}
a+1, & \text { if }(x \% 2) !=0 \\
5-a, & \text { Otherwise }
\end{aligned}\right.
$$

$$
\begin{array}{ll}
f(x) & =\text { Urutan pertanyaan } \\
a & =\text { Poin SUS dari evaluasi } \\
(x \% 2) !=0 & =\text { Ganjil }
\end{array}
$$


3. Skor SUS yang sudah dihitung sebelumnya pada poin 1 dan 2 dijumlahkan dan dikalikan dengan 2,5.

4. Menghitung skor rata-rata masing-masing responden dengan menjumlahkan semua skor dibagi dengan jumlah responden.

Berikut rumus yang digunakan untuk menghitung skor rata-rata SUS:

Keterangan:

$$
\bar{x}=\frac{\sum x}{n}
$$

$\bar{x}=$ Skor rata-rata

$\sum x=$ Jumlah skor SUS

$n=$ Jumlah responden

Tabel 2. Analisis SUS pada Heuristic Evaluation

\begin{tabular}{|c|c|c|c|c|c|c|c|c|c|c|c|c|c|c|c|c|}
\hline \multirow{2}{*}{$\mathrm{E}$} & \multicolumn{7}{|c|}{ Skor Asli } & \multicolumn{7}{|c|}{ Skor Hasil Hitung } & \multirow{2}{*}{ Jumlah } & \multirow{2}{*}{$\begin{array}{c}\text { Nilai } \\
\text { (Jumlah X } \\
2,5)\end{array}$} \\
\hline & Q1 & Q2 & Q3 & Q4 & Q5 & Q6 & Q7 & Q1 & Q2 & Q3 & Q4 & Q5 & Q6 & Q7 & & \\
\hline 1 & 2 & 3 & 3 & 4 & 4 & 3 & 1 & 1 & 2 & 2 & 1 & 3 & 2 & 0 & 11 & 28 \\
\hline 2 & 2 & 3 & 3 & 4 & 4 & 3 & 1 & 1 & 2 & 2 & 1 & 3 & 2 & 0 & 11 & 28 \\
\hline 3 & 3 & 3 & 3 & 4 & 4 & 2 & 1 & 2 & 2 & 2 & 1 & 3 & 3 & 0 & 13 & 33 \\
\hline \multicolumn{16}{|c|}{ Skor Rata-rata (Hasil Akhir) } & 29 \\
\hline
\end{tabular}

Pada Tabel 2, E kepanjangan dari evaluator. Evaluator pada evaluasi ini berjumlah 3 orang. Q1 sampai Q7 adalah jumlah dari pertanyaan heuristic checklist. Skor asli adalah skor mentah yang didapat dari evaluator dan skor hasil hitung adalah skor yang sudah dihitung mengikuti ketentuan SUS. Jumlah adalah hasil penjumlahan tiap nilai pada skor hasil hitung, sedangkan nilai adalah hasil perkalian jumlah dengan 2,5. Skor rata-rata atau hasil akhir didapat dari hasil penjumlahan nilai dibagi dengan jumlah evaluator. Hasil rata-rata perhitungan SUS pada heuristic evaluation adalah 29 poin dan poin ini jauh dibawah standar rata-rata SUS yaitu 68 poin.

\subsection{Think-aloud}

Evaluasi Think-aloud (TA) sama dengan HE yang menggunakan kuesioner Heuristic Checklist (HC), yang juga terbagi menjadi 2 jenis penilaian yaitu berdasarkan komentar dan penilaian rating SUS. Hasil penilaian komentar dapat dilihat pada Tabel 4.

Tabel 3. Analisis Komentar pada evaluasi Think-aloud (TA)

\begin{tabular}{|l|l|l|}
\hline No & $\begin{array}{c}\text { Heuristic } \\
\text { Checklist } \text { (HC) }\end{array}$ & \multicolumn{1}{c|}{ Temuan } \\
\hline 1 & HC01 & $\begin{array}{l}\text { - Desain kurang menunjukkan visibilitas sistem } \\
\text { - Tampilan tidak konsisten } \\
\text { - Filter membingungkan } \\
\text { - Kecepatan masih lambat } \\
\text { - Buka halaman dengan tab baru shorcut ctrl+klik menyebabkan } \\
\text { blank beberapa detik pada halaman sebelumnya. }\end{array}$ \\
\hline 2 & HC02 & $\begin{array}{l}\text { Konten/ informasi yang terlalu banyak membingungkan } \\
\text { - Tombol Close/Keluar tidak ada saat lihat gambar } \\
\text { - Tombol Next/Selanjutnya tidak ada saat lihat gambar }\end{array}$ \\
\hline
\end{tabular}




\begin{tabular}{|l|l|l|}
\hline No & $\begin{array}{c}\text { Heuristic } \\
\text { Checklist } \text { (HC) }\end{array}$ & \multicolumn{1}{c|}{ Temuan } \\
\hline & & $\begin{array}{l}\bullet \text { Tombol Preview/sebelumnya tidak ada saat lihat gambar } \\
\text { Hanya fungsi shortcut standar yang bisa dijalankan pada } \\
\text { aplikasi (Ctrl + C, Ctrl + V, Ctrl + Z) }\end{array}$ \\
\hline 4 & HC05 & $\begin{array}{l}\bullet \text { Pesan } \text { error tata bahasanya membingungkan } \\
\text { Tampilan } \text { error message tidak efektif }\end{array}$ \\
\hline 5 & HC06 & Hover kurang terlihat \\
\hline 6 & HC08 & Pembatas tiap bagian tidak jelas \\
\hline 7 & HC10 & Menu help tidak tersedia \\
\hline
\end{tabular}

Penilaian Software Usability System (SUS) dihitung menggunakan rumus pada bagian 3.1. Hasil penilaian Think-aloud dapat dilihat pada Tabel 4.

Tabel 4. Analisis SUS pada evaluasi Think aloud

\begin{tabular}{|c|c|c|c|c|c|c|c|c|c|c|c|c|c|c|c|c|}
\hline \multirow{2}{*}{$\mathbf{R}$} & \multicolumn{7}{|c|}{ Skor Asli } & \multicolumn{7}{|c|}{ Skor Hasil Hitung } & \multirow{2}{*}{ Jumlah } & \multirow{2}{*}{$\begin{array}{c}\text { Nilai } \\
(\text { Jumlah } \times 2.5)\end{array}$} \\
\hline & Q1 & Q2 & Q3 & Q4 & Q5 & Q6 & Q7 & Q1 & Q2 & Q3 & Q4 & Q5 & Q6 & Q7 & & \\
\hline 1 & 2 & 1 & 1 & 4 & 2 & 1 & 1 & 1 & 4 & 0 & 1 & 1 & 4 & 0 & 11 & 28 \\
\hline 2 & 3 & 4 & 2 & 3 & 2 & 2 & 1 & 2 & 1 & 1 & 2 & 1 & 3 & 0 & 10 & 25 \\
\hline 3 & 2 & 2 & 2 & 3 & 2 & 1 & 1 & 1 & 3 & 1 & 2 & 1 & 4 & 0 & 12 & 30 \\
\hline 4 & 3 & 1 & 2 & 2 & 5 & 2 & 1 & 2 & 4 & 1 & 3 & 4 & 3 & 0 & 17 & 43 \\
\hline 5 & 3 & 2 & 4 & 2 & 3 & 2 & 1 & 2 & 3 & 3 & 3 & 2 & 3 & 0 & 16 & 40 \\
\hline 6 & 4 & 4 & 2 & 2 & 4 & 5 & 1 & 3 & 1 & 1 & 3 & 3 & 0 & 0 & 11 & 28 \\
\hline 7 & 2 & 2 & 2 & 2 & 3 & 3 & 1 & 1 & 3 & 1 & 3 & 2 & 2 & 0 & 12 & 30 \\
\hline 8 & 3 & 1 & 2 & 4 & 3 & 1 & 1 & 2 & 4 & 1 & 1 & 2 & 4 & 0 & 14 & 35 \\
\hline 9 & 4 & 1 & 2 & 3 & 4 & 3 & 1 & 3 & 4 & 1 & 2 & 3 & 2 & 0 & 15 & 38 \\
\hline 10 & 5 & 1 & 4 & 2 & 3 & 1 & 1 & 4 & 4 & 3 & 3 & 2 & 4 & 0 & 20 & 50 \\
\hline & & & & & Sko & or Ra & ta-ra & $\operatorname{ta}(H$ & asil $A$ & Akhi & & & & & & 35 \\
\hline
\end{tabular}

Pada Tabel 4, R berarti responden, di mana responden pada metode Think aloud berjumlah 10 orang. Q1 sampai Q7 adalah jumlah dari pertanyaan Heuristic checklist. Skor asli adalah skor mentah yang didapat dari responden dan skor hasil hitung adalah skor yang sudah dihitung mengikuti ketentuan SUS. Jumlah adalah hasil penjumlahan skor hasil hitung, sedangkan nilai didapat dari 2,5 dikalikan jumlah. Skor rata-rata atau hasil akhir didapat dari hasil penjumlahan nilai dibagi dengan jumlah responden. Hasil rata-rata perhitungan SUS pada heuristic evaluation adalah 35 poin dan poin ini masih dibawah standar rata-rata SUS yaitu 68 poin.

\subsection{Penggabungan Hasil Evaluasi}

Hasil evaluasi menggunakan Heuristic Evaluation (HE) dan Think-aloud (TA) selanjutnya digabungkan untuk mendapatkan hasil keseluruhan evaluasi. Hasil penggabungan dapat dilihat pada Subbab 3.3.1 dan 3.3.2.

\subsubsection{Penggabungan hasil evaluasi komentar}

Hasil dari penilaian komentar HC yang digabungkan dari bagian 3.1 dan 3.2 dapat dilihat pada Tabel 5. 
Tabel 5. Penggabungan Evaluasi Penilaian Komentar

\begin{tabular}{|l|l|l|}
\hline No & $\begin{array}{c}\text { Heuristic } \\
\text { Checklist } \text { (HC) }\end{array}$ & \multicolumn{1}{c|}{ Temuan } \\
\hline 1 & HC01 & $\begin{array}{l}\text { - Desain tidak menunjukkan visibilitas sistem keseluruhan } \\
\text { - Tampilan tidak konsisten } \\
\text { - Filter membingungkan } \\
\text { - Sistem lambat } \\
\text { - Buka halaman di tab baru dengan shorcut ctrl+klik } \\
\text { menyebabkan blank beberapa detik pada halaman } \\
\text { sebelumnya. }\end{array}$ \\
\hline 2 & HC02 & $\begin{array}{l}\text { Konten/informasi banyak dan membingungkan } \\
\text { - Tombol Close/Keluar tidak ada saat lihat gambar } \\
\text { - Tombol Next/Selanjutnya tidak ada saat lihat gambar } \\
\text { - Tombol Preview/sebelumnya tidak ada saat lihat gambar } \\
\text { - Hanya fungsi shortcut yang bisa dijalankan pada aplikasi } \\
\text { (Ctrl + C, Ctrl + V, Ctrl + Z) }\end{array}$ \\
\hline 3 & HC03 & $\begin{array}{l}\text { - Pesan } \text { error tata bahasanya membingungkan } \\
\text { - Tampilan } \text { error message tidak efektif }\end{array}$ \\
\hline 4 & HC05 & Hover kurang terlihat \\
\hline 5 & HC06 & Pembatas tiap bagian/sections konten tidak jelas \\
\hline 6 & HC08 & Menu help belum tersedia \\
\hline 7 & HC10 &
\end{tabular}

\subsubsection{Penggabungan hasil SUS}

Sebelum digabungkan, perlu dihitung terlebih dahulu nilai SUS metode Heuristic dan Think aloud. Tabel 6 di bawah ini adalah hasil penggabungan perhitungan SUS.

Tabel 6. Penggabungan penilaian SUS

\begin{tabular}{|c|l|ll|}
\hline$\underline{\mathrm{No}}$ & \multicolumn{2}{|c|}{ Metode } & \multicolumn{1}{c|}{ Nilai rata-rata SUS } \\
\hline 1 & Heuristic & 29 \\
\hline 2 & Think Aloud & 35 \\
\hline \multicolumn{2}{|c|}{ Total rata-rata = Jumlah rata-rata / 2} & 21.3 \\
\hline
\end{tabular}

Hasil penggabungan SUS dihitung dengan menambahkan nilai SUS masing-masing evaluasi dan membaginya dengan 2 maka didapat nilai 21,3. Nilai SUS yang jauh dibawah nilai rata-rata yaitu 68 poin mengindikasikan ada masalah pada usability website Rumahdijual.com dan perlu adanya perbaikan pada usability website terkait dengan pointpoint yang tercatat pada Heuristic checklist.

\subsection{EVALUASI}

Hasil evaluasi penilaian SUS didapatkan rata-rata nilai 33,5. Nilai ini jauh dibawah standar nilai rata-rata yaitu 68 poin. Hal ini mengindikasikan ada masalah pada usability aplikasi dan perlu adanya perbaikan pada usability website terkait dengan poin-poin yang tercatat pada Heuristic checklist. Hasil analisis berdasarkan komentar pada evaluasi Heuristic dan Think-aloud hampir sama. Akan tetapi pada hasil evaluasi Think-aloud pengguna lebih banyak menemukan permasalahan UX, sedangkan pada evaluasi Heuristic lebih banyak ditemukan kesalahan UI. Berikut ini adalah kekurangan UI/UX yang ditemukan dari evaluasi think-aloud yaitu:

1. Pada Visibility of system status (HC01) pengguna menemukan filter membingungkan, kecepatan sistem lambat, tampilan tiap halaman tidak konsisten dan saat membuka page 
dengan new tab menggunakan shortcut $\mathrm{Ctrl+click}$ menyebabkan halaman blank untuk beberapa saat.

2. Pada Error prevention (HC05) ditemukan error message yang tidak secara langsung menunjukkan letak kesalahan, tetapi harus melewati trigger tambahan yang harus diproses terlebih dahulu.

3. Pada User control and freedom (HC03) ditemukan tombol pembesar kadang tidak berfungsi saat melihat gambar.

Berdasarkan hasil analisis penggabungan analisis Heuristic dan Think-aloud disarankan tampilan aplikasi untuk diperbaharui, sehingga tujuan untuk memudahkan pengguna menggunakan aplikasi dapat tercapai. Berikut ini adalah saran perbaikan UI/UX antara lain:

1. Pengurangan konten / informasi pada sistem dan menampilkan informasi yang penting saja.

2. Error prevention perlu perbaikan tata bahasa dan tampilannya, agar informasi yang ditampikan jelas.

3. Penambahan fitur tutup gambar, lihat gambar sebelumnya, dan berikutnya.

4. Pastikan tombol pembesar saat melihat gambar dapat berfungsi,.

5. Pastikan proses buka tab dengan $c t r l+k l i k$ berjalan cepat dan pada halaman sebelumnya tidak blank.

6. Perjelas hover agar bisa lebih terlihat.

7. Perjelas pembagian komponen halaman website (garis, spasi, posisi) agar terlihat jelas dan konsisten.

8. Tambah fitur next, previous dan tutup saat melihat gambar.

9. Perlu optimalisasi pada aplikasi agar kecepatan akses sistem dapat ditingkatkan.

10. Sediakan fitur bantuan/dokumentasi.

\section{KESIMPULAN}

Berdasarkan evaluasi dan analisis yang sudah dilakukan, ditemukan beberapa poin kesimpulan yaitu sebagai berikut:

1. Cara menggabungkan metode Heuristic Evaluation (HE) dan Think-Aloud (TA) adalah dengan menggunakan Heuristic Checklist (HC). HC berisikan 10 Heuristic Usability yang membantu penyedia evaluasi untuk mengelompokkan kekurangan tampilan yang ditemukan evaluator pada metode Heuristic dan responden pada metode Think-aloud. Kemudian evaluasi dinilai berdasarkan komentar dan data rating System Usability Scale (SUS). Hasil evaluasi masing-masing metode akan dianalisis dan digabungkan.

2. Cara melakukan evaluasi tampilan (UI) menggunakan penggabungan metode Heuristic dan Think-aloud supaya sesuai dengan prinsip user experience (UX) yang baik, dilakukan dengan penggunaan Heuristic Checklist (HC) yang berisikan 10 Heuristic Usability. Dari 10 poin Heuristic Usability hanya dipilih 7 poin yang terdiri dari:

a. Visibility of system status (HCO1) - Tampilan dan kendali yang ada pada sistem berkesesuaian dengan fungsinya.

b. User control and freedom (HCO3) - Pengguna bebas melakukan suatu tugas dan sistem harus memiliki fitur undo dan redo.

c. Error prevention (HCO5) - Sistem dirancang dengan baik dengan tingkat kesalahan pengoperasian sangat kecil.

d. Recognition rather than recall (HCO6) - Instruksi singkat, jelas dan mudah diakses.

e. Flexibility and efficiency of use (HCO7) - Sistem dapat dioperasikan secara mudah oleh pengguna baik yang berpengalaman ataupun belum berpengalaman.

f. Aesthetic and minimalist design (HCO8) - Sistem menampilkan informasi yang harus diketahui oleh user dengan tepat. 
g. Help and documentation (HC10) - Ketersediaan fitur bantuan atau dokumentasi singkat pada sistem.

3. Hasil analisis penggabungan Heuristic dan Think-aloud menunjukkan bahwa aplikasi perlu diperbaharui, berikut ini adalah saran-saran perbaikan UI/UX hasil evaluasi:

a. Pengurangan konten / informasi pada sistem dan menampilkan informasi yang penting saja.

b. Error prevention perlu perbaikan tata bahasa dan tampilan error message, agar informasi yang ditunjukkan jelas.

c. Penambahan fitur tutup gambar, lihat gambar sebelumnya, dan berikutnya.

d. Pastikan tombol pembesar saat melihat gambar dapat berfungsi,.

e. Pastikan proses buka tab dengan ctrl+klik berjalan cepat dan pada halaman sebelumnya tidak blank.

f. Perjelas hover agar bisa lebih terlihat.

g. Perjelas pembagian komponen halaman website (garis, spasinya, posisi) agar terlihat jelas dan konsisten.

h. Tambah fitur next, previous dan tutup saat melihat gambar.

i. Perlu optimalisasi pada aplikasi agar kecepatan akses sistem dapat ditingkatkan

j. Buat fitur bantuan.

\section{DAFTAR PUSTAKA}

[1] Alexander, Alvin, 2018, 15 Situs Properti Terpopuler di Indonesia, diakses: 1 Agustus 2021, URL: <https://www.kompasiana.com/alvinalexander/5acb559a16835 f0ea850f134/15-website-properti-terpopuler-di-Indonesia>

[2] Alroobaea, Roobaea \& Mayhew, P.J.. (2014). How Many Participants are Really Enough for Usability Studies?. Proceedings of 2014 Science and Information Conference, SAI 2014. 10.1109/SAI.2014.6918171.

[3] Jackson, F., \& Cheng, L. (2018). UX in Practice: Applying a Heuristic Evaluation Technique to Real World Challenges. Proceedings of the Human Factors and Ergonomics Society Annual Meeting, 62(1), 702-703.

[4] Virzi, RA, Sorce, JF, \& Herbert, LB (1993). Perbandingan Tiga Metode Evaluasi Kegunaan: Heuristik, Think-Aloud, dan Pengujian Kinerja. Prosiding Pertemuan Tahunan Human Factors and Ergonomics Society , 37 (4), 309-313.

[5] Nielsen, J., and Molich, R. (1990). Heuristic evaluation of user interfaces, Proc. ACM CHI'90 Conf. (Seattle, WA, 1-5 April), 249-256.

[6] Sugiyono. 2009. Metode Penelitian Kuantitatif-Kualitatif dan R\&D. Bandung: Alfabeta.

[7] Usability.gov. (n.d.). System Usability Scale (SUS). Retrieved from http://www.usability.gov/how-to-and-tools/methods/system-usability-scale.html 